\section{CLÁSICOS Y MODERNOS: DOS ADAPTACIONES LITERARIAS DE ORSON WELLES}

\author{
Vicente Molina Foix \\ Escritor
}

\begin{abstract}
The main purpose of this paper is to study the importance of Orson Welles as filmmaker in two different ways. Firstly, as regards his adaptations from Shakespeare's texts. Among these Macbeth, focusing mainly on Jacques Tourner's influence with his work I walked with a Zombie and the strategies used to build a film using fantastic terror clues. In the second part of the paper, Welles is studied in relation to his interest in Isak Dinesen's work and his adaptation from The Inmortal Story.
\end{abstract}

KEY WORDS: Shakespeare; Orson Welles; King Lear; Macbeth; The Merchant of Venice; Othello; The Tempest; Chimes at Midnight; Touch of Evil; Mr. Arkadin; The Inmortal Story; Yhe Dreamers; Kurosawa; The Bad Sleep Well; Jacques Tourneur; Cat People; I walked with a Zombie; The Leopard Man; Jean Luc Godard; Detective; Isak Dinesen.

La obra dramática de William Shakespeare es un lugar común de las adaptaciones literarias a la gran pantalla, pero dentro de ese vasto territorio iniciado en los albores del cinematógrafo y hoy en plena expansión, quiero circunscribirme a un trabajo de Orson Welles (junto a Kurosawa el autor, a mi juicio, de las más grandes obras maestras inspiradas por el dramaturgo isabelino), reivindicando la modernidad formal de su mirada al clásico, que incluye naturalmente, además de sus cuatro trabajos "shakesperianos", el Don Quijote de Cervantes, y las dos novelas contemporáneamente clásicas de Kafka y Dinesen. $Y$ es que este cineasta sin escuela y sin secuela, sin discípulos, sin hogar fílmico preciso, que inició poco menos que adolescente una carrera arrolladora y fulgurante -desde el comienzo renovadora de las normas lingüísticas del cine patentadas por los tres grandes genios de la primera "ola" del cine mudo, Griffith, Murnau y Eisenstein-, a partir de su quinto largometraje, Macbeth, refunda asimismo el sistema de adaptación al cine del texto literario, con estrategias que le son propias y continúan siendo modélicas, por no decir canónicas.

Mi propuesta, en suma, es la de considerar a Welles no únicamente como uno de los grandes directores "modernos"

\section{CLASSIC AND MODERN: TWO LITERARY ADAPTATIONS BY ORSON WELLES}

RESUMEN: Se estudia la trayectoria cinematográfica de Orson Welles con especial referencia a las adaptaciones de las obras de Shakespeare y dentro de ellas Macbeth, destacando la influencia de Jacques Tourner con su obra Yo anduve con un Zombie y construyendo su obra con los parámetros del cine de terror fantástico. Se describe el interés de Wells por la obra de Isak Dinesen y su adaptación de Una historia inmortal.

PALABRAS CLAVE: Shakespeare; Orson Welles; Rey Lear; Macbeth; El mercader de Venecia; Otelo; La tempestad; Campanadas a medianoche; Sed de mal; Mr. Arkadin; Una historia inmortal. Los soñadores; Kurosawa; Los canallas duermen en paz; Jacques Tourneur; la mujer pantera; Yo anduve con un zombie; El hombre leopardo; Jean Luc Godard; El detective; Isak Dinesen.

en sus tres películas unánimemente tenidas por seminales (Ciudadano Kane, El cuarto mandamiento, La dama de Shangai), y que son las que, con gracia, François Truffaut llamaba las películas "hechas con la mano derecha", sino también, siguiendo de nuevo a Truffaut, destacar las que Welles hizo con la mano izquierda, las policiacas (El extranjero, Sed de $m a l)$, las que sufrieron cortes o graves interferencias en la producción (Mr. Arkadin, Otelo), y, principal y detenidamente, en la por algunos menospreciada Macbeth y en el mediometraje de formato anómalo de su última etapa europea Una historia inmortal.

Welles tuvo una obsesión permanente con Shakespeare, que empezaría cuando, con diez años de edad, se hizo fotografiar vestido de Rey Lear y maquillándose la cara para dar la imagen de un anciano. Por una terrible ironía del destino, dos o tres semanas antes de su muerte inesperada de un ataque al corazón. Welles volvió a retratarse para una revista norteamericana como Lear -ahora con la edad y el físico adecuado- $y$, una vez más en su accidentada carrera, tratando de promocionar la adaptación cinematográfica de esa obra maestra de Shakespeare que llevaba años elaborando y para la que tenía el guión escrito y el 
reparto hecho, reservándose él, naturalmente, el papel del rey, con un vestuario "ad hoc" ya confeccionado de acuerdo al gran volumen de su cuerpo. La película nunca se hizo, pero esas dos fotos separadas por sesenta años marcan toda una vida de militancia shakesperiana.

En el teatro, Welles realizó muchos montajes de o a partir de Shakespeare, no sólo en su famoso período americano al frente del Mercury Theatre sino también, aún adolescente, interpretando importantes papeles de distintas obras del Bardo en Dublín y Londres. La primera adaptación que hizo de Macbeth fue en la radio, otro medio, como es sabido, de capital importancia en la obra de Welles. A menudo, el director nacido en Wisconsin retoma y altera de uno a otro medio un material previo de origen shakesperiano: de la radio al teatro, del libreto escénico al guión de cine. Así sucedió, como veremos más adelante, en el caso de sus "macbeths", y en el de un comercialmente fracasado montaje teatral que estrenó en Boston en 1938, Cinco reyes, reciclado casi treinta años después en esa obra maestra cinematográfica que es Campanadas a medianoche.

A veces, Welles se mostró como un manipulador y "recortador" no menos drástico y sujeto a la oportunidad del momento de lo que lo fue su idolatrado maestro británico cuando trabajaba en los teatros isabelinos. Una de las grandes pérdidas, quizá no irreparable, de su filmografía es El mercader de Venecia que el director filmó enteramente en Yugoslavia, dándolo por terminado y montado, y en el que él, en medio de un pintoresco reparto internacional, interpretaba al prestamista judío Shylock. Pues bien, esta película que, por complejos problemas de derechos y el robo, quizá relacionado, de dos bobinas de los laboratorios de Roma donde se ultimaba su post-producción, sigue manteniendo hoy la condición tantalizante de obra fantasma, secuestrada más que perdida, tuvo en su preparación un episodio muy elocuente. El papel de la rica heredera Porcia, junto al del mercader y el del prestamista el más importante del drama y yo diría que uno de los grandes roles femeninos del canon shakesperiano, lo iba a encarnar la entonces compañera sentimental (y hoy viuda) de Welles, Oja Kodar. Pero al empezar los ensayos previos a la filmación la actriz yugoslava se dio cuenta, sin que su marido tuviera que manifestárselo, de que su inglés era demasiado imperfecto para un personaje de tanta relevancia, dramática y verbal, tomando por sí misma la decisión de descolgarse del reparto. Entonces, Welles, en un gesto tal vez situado entre la fidelidad amorosa y la conveniencia económica, en vez de llamar a otra actriz inglesa suprimió el papel de Porcia. No sabemos aún, mientras no aflore a la luz este film maldito, cómo suplió Welles la carencia, y de qué modo afectó, por ejemplo, a la inexcusable escena del juicio y la libra de carne, donde la Porcia de Shakespeare, disfrazada de leguleyo, lleva todo el peso de la acción.

El Macbeth filmico de Welles procede de una frecuentación shakesperiana que, más allá de la obsesión que revelaba anecdóticamente el citado episodio de las dos fotos y de modo más substancial sus numerosas recreaciones, apunta a una profunda identificación con el dramaturgo de Stratford. La película de 1948 es por lo demás un ejemplo de cómo desacralizar un texto sagrado sin cambiar su esencia, es decir, sin convertirlo en un mero soplo inspirador (asi lo hizo Kurosawa en su poco conocida Los canallas duermen en $p a z$, basada en Hamlet) o en un ingenioso juego de conveniencia, como el Detective de Jean Luc Godard, con sus ecos de La tempestad. En Macbeth, como cuatro años después en Otelo, Welles toma literalmente la obra de Shakespeare, de la que conserva muchos pasajes y parlamentos íntegros, pero aquí con una trascendental reforma o socavamiento del original, añadiéndole los atributos más rotundos del género, en este caso del cine gótico. $Y$ de ese modo, el Macbeth wellesiano se convierte en un film de terror dentro de una cierta tradición del "gothick" anglo-americano, sin por ello descoyuntar o violentar los supuestos dramáticos sobre los que se asienta la obra de teatro.

La película comienza, como la pieza, con las tres brujas en función de Parcas, leyendo y anticipando el destino del guerrero Macbeth; la novedad iconográfica es hacer de ellas unas aparecidas de película de magia y hechicería. La coincidencia formal, primera de todas las que, en esta vena de horror expresionista, se dan en el film, la acerca a otras cintas de la década del 40 , realizadas bajo el sello de un personalísimo productor, Val Lewton, a quien se deben, entre otras magnificas películas, las que Ilevan la firma del gran director Jacques Tourneur: La mujer pantera, Yo anduve con un zombie y El hombre leopardo. Por estrambótica que pueda parecer mi afirmación, yo sostengo que el Macbeth de Welles debe mucho en su visualización, en su tratamiento fotográfico y en ciertos elementos de iconografía a Yo anduve con un zombie. El punto de unión más evidente, la introducción de los elementos de la magia 
vudú, tan esenciales en el film de Tourneur (que data de 1943), no puede hacer olvidar, desde luego, que Welles también partía de un precedente propio, su montaje en el Teatro Lafayette de Nueva York, en 1936, de un Ilamado Voodoo Macbeth. Para su puesta en escena teatral, Welles traslada la acción desde Escocia a Haití, adquiriendo gran importancia la presencia de algunos actores/personajes negros y una partitura especialmente escrita para la función por el compositor Virgil Thomson, con profusa utilización de motivos antillanos y una percusión caribeña.

En la película de Welles, a su vez, tiene un significativo protagonismo el muñeco con el que las tres brujas, intermitentemente aparecidas a lo largo de toda la duración, no dejan de hacer ritos del vudú: le ponen al comienzo una pequeña corona anticipando la criminal sucesión de Macbeth al trono, le van clavando agujas en el cuerpo y al final lo destruyen en anuncio de la propia muerte del rey usurpador. A este respecto, y además de otros rasgos estilísticos del género (en la angulación de los planos, en el montaje enfático), la película se cierra en clave expresionismo gótico, cuando de nuevo las brujas, en un episodio que no figura en el texto de Shakespeare, reaparecen para reírse grotescamente del destino trágico de Macbeth, muerto por el sortilegio que ellas le echaron.

La tragedia de Shakespeare tiene por supuesto un clima mortecino y funesto, pero Welles lo acentúa en una concentración espacial que el cine, dada su tendencia expansiva y abierta, hace más atosigante. Todo el film está rodado en decorados, que a menudo parecen no tener ni aire ni salida, y el exacerbado contraste de claroscuros en la fotografía, tan propia del expresionismo germano y, a través de su influjo, de todo el cine en blanco y negro de Welles, aquí está llevada a un paroxismo aterrador. La galería de apariciones de ultratumba y horrendos crímenes procede del original shakesperiano; Welles la hace imagen de un género en su momento -antes de la llegada del "gore"- muy noble por sus filiaciones expresionistas, surrealistas, goyescas y "malditistas", inclinando la historia hacia un tipo de cine de terror fantástico protagonizado por monstruosos "overreachers". Y así, Lord y Lady Macbeth acaban siendo en el film de Welles no muy distintos de los "dráculas", "frankensteins", "doctores moreaus" y demás personajes del macabro fanatismo narcisista tan frecuentado por el séptimo arte.

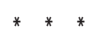

Aunque no tan continuada ni tan intensa como la de Shakespeare, hubo en la vida de Welles otra gran pasión literaria, sentida por las novelas y cuentos de la baronesa Karen Blixen, quizá más conocida como Isak Dinesen. Siempre me ha parecido lógica esa fascinación del megalómano por una miniaturista como ella, tan atípica y tan extemporánea como el propio Welles. Dinesen realiza su obra narrativa en los años que transformaron el mundo de la prosa novelística, pero lo hace al margen de esos sistemáticos asaltos al palacio de la gran novela decimonónica. Dinesen no es proustiana ni desde luego joyceana, no es analítica ni alegórica al modo de Musil o Mann, su territorio particular en nada coincide con el de otro paisajista imaginario como Faulkner, y tampoco su fantasía errante roza el negro visionario de Kafka. El reino literario de Dinesen abunda en niños-gnomos y cuartos encantados, en cortes milagrosas, buques-fantasma y tropiezos con el Buen Dios, y nunca, sin embargo, nos resulta arcaico. Leemos sus cuentos, hoy como en 1950, convencidos de que la suya es una escritura moderna; no novedosa ni siquiera reformadora pero moderna en el sentido central, baudelairiano, del término. El perfil inestable y aun paradójico que da a sus personajes, el juego especular de máscaras y digresiones, la tonalidad irónica de la voz narradora, son recursos propios de una inteligencia literaria que ha hecho suyas las grandes crisis contemporáneas del relato.

[Ambos, la escritora danesa y el cineasta americano, son suntuosos y hasta recamados en la escritura, de una sutileza excepcional, y los dos se sienten más que cómodos, espoleados/aguijados por los viejos géneros de la fábula, la leyenda y el apólogo terrible.]

Welles conoció muy pronto la obra de la baronesa, cuando únicamente unos "happy few" (Truman Capote, Hemingway, Carson McCullers, Arthur Miller entre ellos) la seguian y admiraban. En 1953, el autor de Ciudadano Kane estuvo a punto de filmar, para una película de sketches que iba a producir Alexander Korda, El viejo caballero, uno de los relatos de Siete cuentos góticos. La película no se hizo, y el cineasta y la escritora nunca se encontraron, habiéndose él perdido el almuerzo neoyorkino en honor de Dinesen que Carson McCullers dio en 1959, y al final del cual, se cuenta, Marilyn Monroe, otra admiradora de sus libros, bailó con la baronesa encima de la mesa del restaurante. Poco tiempo después, según le cuenta a Peter Bogdanovich en su libro de conversaciones, Welles viajó ex profeso a Copenhague

ARBOR CLXXXVI 741 enero-febrero [2010] 53-58 ISSN: 0210-1963 
para conocer a Dinesen, pero una vez allí no salió del hotel en los tres días pasados en la capital danesa. Sin embargo, al abandonar la ciudad empezó a escribirle una carta de amorosa admiración a la escritora, que, sin dejar de seguir redactando en los meses siguientes, no llegó a tiempo de mandarle antes de que ella muriera (en 1962).

Después vendría (entre 1966 y 1968) la adaptación cinematográfica de Una historia inmortal, otro proyecto antiguo de Welles que sólo se materializó gracias a la financiación de la segunda cadena de la Televisión Francesa, donde tenía que emitirse en estreno absoluto el 24 de mayo de 1968; los sucesos que entonces vivía Francia, y la consiguiente huelga del organismo audiovisual de la O.R.T.F., impidieron esa emisión, siendo después la película (de 58 minutos de duración) estrenada en pantalla grande en el Festival de Cine de Nueva York de aquel año y bastante más tarde en cines de Francia y España. En 1978, el director escribió el guión de un largometraje titulado The Dreamers ("Los soñadores"), basado en la fusión de dos relatos de Dinesen, Ecos y Los soñadores (pertenecientes al ciclo de sus Cuentos góticos). Avanzado el trabajo de localizar exteriores y hacer el reparto, Welles murió en 1985 sin poderlo llevar a cabo.

"He estado enamorado de Isak Dinesen desde que abrí su primer libro", escribió Welles en un pasaje de esa carta nunca enviada, en la que de paso explica el motivo de su extraño comportamiento en Copenhague: "¿Qué podría ofrecer un visitante fortuito más que un agradecimiento tartamudo? El visitante resultaría un plasta, y el enamorado era demasiado humilde y demasiado orgulloso para caer en eso. Pero si me mantenía en silencio, nuestro idilio duraría, en términos íntimos, mientras yo tuviera ojos para leer letra impresa". El amor wellesiano por esa gran romántica de la ironía que fue Karen Blixen quedó plasmado al menos en una obra maestra cinematográfica.

Una historia inmortal es una adaptación fílmica muy literal del cuento largo (76 páginas en mi edición inglesa) que, bajo el título The Inmortal Story (al estrenarse en España se le cambió el artículo) apareció por vez primera en el libro Anécdotas del destino, publicado en inglés (la lengua literaria de la baronesa) en 1958, siendo el último libro narrativo de su autora. La acción del relato está situada en Macao, pero Welles no dispuso de dinero para irse tan lejos. El pueblecito madrileño de Chinchón le serviría de decorado, no muy orientalizado: unas estelas con escritura ideográfica colgando en las fachadas de casas de madera bastante serranas son, junto al paso en la primera secuencia del film de cuatro o cinco chinos de guardarropía, las únicas concesiones al sabor local. Dinesen cuenta la historia de una leyenda realizada con personas de carne y hueso por el deseo de otra; una leyenda del mar que todos los marineros han oído alguna vez en sus travesías y que Welles, quizá en una de sus bromas características, dijo (entrevistado en el año 1982) haber oído él mismo relatar al tripulante de un barco en el que iba de viajero. Según la leyenda, todos los marineros han escuchado alguna vez lo que le sucedió a uno de ellos en algún lugar y en otro tiempo: en una escala de su barco, bajó a tierra sin dinero, estaba paseando por la ciudad, y un gran señor le llamó desde su imponente carricoche para preguntarle si quería ganar cinco guineas. Lo que el marinero -que naturalmente contestó que sí- tenía que hacer era ir a la lujosa mansión del caballero y acostarse con su hermosa mujer, y una vez cumplimentada su obligación sexual, ésa que el anciano señor deseoso de tener descendencia ya era incapaz de cumplir, abandonar la casa al amanecer.

Tanto Dinesen como Welles presentan, con ciertas variaciones sobre el núcleo de la leyenda original, a un anciano y solitario millonario, Mister Clay, que, soltero y sin ningún deseo de paternidad, está obsesionado con "realizarse" artísticamente provocando, pagando y dirigiendo las escenas que darán realidad a la leyenda. ¿Hace falta resaltar lo que pudo atraer al director americano en esta historia y en este personaje de Mister Clay? La cinematografía de Welles está jalonada de complotadores y arteros confabuladores; individuos dotados de la inteligencia astuta, la "mètis" de los griegos, y expertos en los trucos de la inducción y la manipulación de las voluntades: Kane, Arkadin, el Falstaff de Campanadas a medianoche y, sobre todo, el Hank Quinlan de Sed de mal, amañando las pruebas de los casos criminales para forjar su propia leyenda de policia superdotado. Tampoco es ocioso señalar que todas esas figuras maliciosas o perversas, ambiciosas, taimadas, fueron interpretadas por el propio Orson Welles, el más genial manipulador de la industria del cine, siempre en favor del arte del cine.

En el desarrollo fílmico de ese tema de la reorganización de la realidad a través de prácticas manipulativas (una metáfora suprema de la creación artística), Una historia 
inmortal adquiere un valor testamentario. Mister Clay, a través de su criado Elishama, convoca a su mansión a los dos "actores" del complot que ha ideado, la mujer, Virginie (interpretada por la extraordinaria Jeanne Moreau), quien resulta ser la hija de un antiguo rival comercial de Clay, y el marinero (un algo desvaido Norman Eshley). La escenificación de los hechos que conformarian la leyenda se lleva a cabo, pero en el desenlace sucede algo trágico e inesperado: concluida la velada, Mister Clay muere. La mujer, se insinúa, permanecerá en la mansión como dueña, restituyéndosele lo que su padre perdió a manos de su enemigo. Y el marinero, cuando Elishama, el criado de Clay, le entrega las cinco guineas convenidas y le dice, siguiendo los surcos de la vieja leyenda, "ahora ya puedes contar la historia", le da al criado una respuesta sorprendente: "¿Por qué lo llamas historia?" -añadiendo a continuación- "No lo contaría nunca, ni por cien veces cinco guineas".

Mister Clay logra que esa leyenda nunca probadamente sucedida pero siempre contada como fabulación marinera, pueda, a partir de sus estrategias falsarias, responder a la verdad. Ahora bien, el hacedor de la leyenda, el artista que es Clay, no preveía la autonomía de sus peones humanos. A lo largo de esa noche de amor provocada desde fuera, el marinero se enamora de la mujer y propone llevarla con él a su pais, Dinamarca; al final de la representación en la casa del millonario, el marino ya no es el actor pagado por desempeñar un rol, sino un hombre que pretende apropiarse de su vivencia, como la mujer se apropiará de la mansión o espacio legendario. Para ellos dos no hay, así pues, conciencia de supercheria; han vivido un acontecimiento trascendental, y llamarlo cuento o historia sería para ellos una pobre y errónea manera de revivirlo.

El único mortal de esta historia inmortal es el artista, en una cadena de sucesiones idénticas. Primero está el "imaginador" del argumento y las peripecias que lo desarroIlan, la escritora Isak Dinesen, después el "forjador" de las imágenes, Orson Welles, aunque a la postre el "realizador" sea Mister Clay quien entrega su vida a cambio de nada tangible: tan sólo por crear una ficción. El pesimismo artístico reflejado en el desenlace de The Immortal Story tiene, dentro de su similitud, interesantes matices de diferencia entre el relato original y la película. El portavoz de esa melancolía es siempre el mismo, el criado Elishama, que, con palabras de Dinesen, dice, a la muerte repentina de su señor (y traduzco yo mismo): "Es muy duro que la gente desee tanto las cosas que no pueda prescindir de ellas. Si no logran esas cosas resulta muy duro, y cuando las logran seguramente aún lo es más". Al final del cuento escrito, y antes de abandonar la mansión, el joven marinero le da a Elishama una concha marina de color rosáceo para que, por favor, se la entregue como regalo de adiós a la mujer, advirtiéndole que esa concha produce una sonoridad que nunca nadie ha oído antes. Una vez que el marinero se ha ido, el criado se lleva la concha al oído, y tiene, escribe Dinesen "un extraño, suave y profundo shock, surgido del sonido de una nueva voz en la casa y en la historia". Elishama piensa entonces que ese sonido ya antes lo oyó, hace tiempo, hace mucho tiempo. "¿Pero dónde?", se pregunta, antes de deslizar su mano desde la cabeza.

Welles altera ese final mínima pero significativamente. La frase que en el film pronuncia Elishama ante el cadáver recién descubierto de Mister Clay es: "Ha muerto, Miss Virginie; ha esperado al amanecer para beber la copa de su triunfo, pero ha sido demasiado fuerte para él", y la misteriosa "voz nueva" que -como una invocación de ultratumba- dominará la casa, los personajes y el sentido de la historia inmortal es en la película la voz del narrador omnisciente, supremo hacedor de fábulas y trampantojos. Naturalmente, cuando filmó Una historia inmortal, Orson Welles no podía saber que ésa sería su última obra de ficción, pero sin duda vislumbraba el horizonte de un final. No me cabe pensar en una despedida filmica más sublime, a la vez que patética, que el reconocimiento - por parte de uno de los mayores maestros que ha tenido el cine- de la grandeza agónica de toda obra de arte. 


\section{BIBLIOGRAFÍA}

Blixen, Karen (1934). Siete cuentos góticos, Barcelona, Moguer.

\section{FILMOGRAFÍA}

Campanadas a medianoche (Dir. Orson Welles, 1965).

Recibido: 7 de octubre de 2008 Aceptado: 9 de diciembre de 2008
Ciudadano Kane (Citizen Kane, Dir. Orson Welles, 1941).

El detective (Détective, Dir. Jean Luc Godard, 1985).

The Immortal Story (Dir. Orson Welles, 1968). Macbeth (Dir. Orson Welles, 1948). Mr. Arkadin (Dir. Orson Welles, 1955).

Sed de mal (Touch of Evil, Dir. Orson Welles, 1958).

The Tragedy of Othello. The Moor of Venice (Dir. Orson Welles, 1952).

Yo anduve con un zombie (I Walked with a Zombie, Dir. Jacques Tourneur, 1943). 